\title{
REVIEW
}

\section{Problems and Countermeasures of Internal Control Management in High-tech Enterprises}

\section{Yuhuan Zhao*}

Beijing Language and Culture University, Beijing, 100083, China

\begin{tabular}{ll}
\hline ARTICLE INFO & ABSTRACT \\
$\begin{array}{l}\text { Article history } \\
\text { Received: } 12 \text { April } 2019\end{array}$ & $\begin{array}{l}\text { The wave of the socialist market economy has continually invaded, which } \\
\text { has already caused a serious impact on the survival of many enterprises } \\
\text { in China at this stage. In order to obtain development, traditional enter- } \\
\text { Revised: } 22 \text { April } 2019\end{array}$ \\
$\begin{array}{l}\text { prises must follow the trend of the times to carry out their own reform } \\
\text { and progress. For many high-tech enterprises, the most important issue is } \\
\text { how to achieve internal control management, with rationalization means } \\
\text { Published Online: } 31 \text { October 2019 }\end{array}$ & $\begin{array}{l}\text { to gradually promote the corresponding work and economic benefits of } \\
\text { enterprises, not only to save time, but also to improve the corresponding } \\
\text { work efficiency, moreover, it is necessary to be able to promote the es- } \\
\text { tablishment of a relatively complete internal control management system } \\
\text { Keywords: }\end{array}$ \\
in the actual work process of high-tech enterprises, in order to solve and \\
prevent some problems that have emerged or need to be emerged.
\end{tabular}

\section{Introduction}

$\mathrm{W}$ ith the continuous improvement of the development level of information technology, China has made the information system more and more perfect in the process of social construction and urbanization development, which has promoted many high-tech enterprises. For high-tech enterprises, the competitiveness at this stage is so large, and the changes in the information age have gradually stimulated the progress of enterprises, which makes it necessary for an enterprise to maintain its own competitive position in the economic wave, it is necessary to establish a relatively complete internal management control system to ensure the stability and sustainability of its own development.

\section{Connotation Analysis of Enterprise Inter- nal Control Management}

\subsection{Internal Control}

The earliest definition of internal control appeared in the Auditing Standards Notice issued by the Auditing Standards Board (ASB) in 1972 and was defined as follows: the so-called internal control means that under the influence of specific environment and development trends, in order to effectively improve their own experience and efficiency, it is necessary to integrate various resources that can be utilized through appropriate economic control measures, in order to achieve the management objectives originally established by the enterprise itself. ${ }^{[1]}$ Subsequently, in the Internal Control-Integrated Framework

*Corresponding Author:

Yuhuan Zhao,

Beijing Language and Culture University, No. 15 Xueyuan Road, Haidian District, Beijing, 100083, China; E-mail: 453019626@qq.com. 
promulgated by The Committee of Sponsoring Organizations of the Treadway Commission (COSO) under the National Institute of Certified Public Accountants in 1992, it was clearly stated: It is not only the responsibility of the leader to effectively implement the internal control management of the enterprise, but a reasonable process of topdown or bottom-up, together with the board of directors, senior management and employees for achieving the economic efficiency of business operations. ${ }^{[2]}$ The above definitions are all determined by foreign scholars. Combined with China's national conditions, many Chinese scholars believe that internal control refers to a set of institutional arrangements and structural relationships that can maintain formal and informal relationships between various economically relevant and relevant stakeholders within the enterprise. As for the large number of high-tech enterprises existing at the current stage, the increasing competitiveness has also created important challenges for achieving good internal control management. In order to enable certain work management objectives to be effectively implemented, it is to maintain a stable and balanced state of mutual restraint through the rights and responsibilities between the various subjects and participants, which will ensure that the corresponding efficiency and fairness are achieved in the final work process. ${ }^{[3]}$

\subsection{The Theoretical Basis of Internal Control Management $^{[4]}$}

The first and most basic theory is cybernetics. The socalled cybernetics, it believes that the implementation of the corresponding work is to be able to combine the development of information technology and the continuous impact of the modern wave, a way to control and regulate the organization and system within the enterprise, moreover, because in the work process of the enterprise, many departments are composed of a certain level and structure, which is equivalent to an organic whole with special functions. Moreover, after the establishment of this organic whole, it can continuously receive the information and energy from the outside world, and process and process the received information through the change of mechanism in its own internal environment, thereby bringing new information and theoretical foundation to the development of the enterprise. The second theoretical basis refers to the principal-agent theory, which is due to the characteristics of modern corporate enterprises_-a normal agency relationship derived from the separation of management rights and ownership. But once such a normal agency relationship has a corresponding divergence in the actual operation process, once this disagreement is not solved well, serious economic damage will occur, and there is no specific guarantee for the development of the enterprise itself and the interests of all classes, especially workers. At this time, the enterprise accounting internal control optimization system established can minimize the occurrence of information asymmetry and transform all the goals and approaches into a highly unified model, which will enable the enterprise to firmly establish itself in a solid development position in the fierce market competition. The third theory is relatively complicated, and it is a game theory derived from the rational assumptions of behavioral subjects.

The emergence of such a theory enables the subjects of each hypothetical behavior to be able to abide by the agreement under the relatively rational control conditions, so that the ultimate goal of the ultimate corporate economy can be achieved. ${ }^{[5]}$

\section{The Problems of Status Quo of Internal Control Management in High-Tech Enter- prises}

First of all, one of the most obvious features is that in the process of implementing the actual internal management of high-tech enterprises in China, few enterprises will have a sound organizational structure, often due to the upper-level leaders and the board of directors. Even if the corresponding internal management and supervisory personnel are set up, their functions will be restricted by the higher authorities, and they will be ineffective. Secondly, the economic managers inside high-tech enterprises have not given high priority to the corresponding control and management measures, which has caused the enterprises to implement certain incentive and restraint mechanisms, resulting in serious work inefficiencies. ${ }^{[6]}$

\section{Countermeasures for Solving the Problems of Status Quo of Internal Control Manage- ment in High-tech Enterprises}

\subsection{Strengthen Internal Integration and Form a Unified Goal}

As far as the internal control management of high-tech enterprises in this stage of China is concerned, there are serious distortion problems, which will not only seriously affect the smooth progress of internal accounting work, but also bring about a negative development trend for the industry development. In order to effectively adjust the stability of the social economy and related development trends, the State Council clearly states in Article 27 of the "Accounting Law" that: It is essential to require all enterprises and institutions to establish internal control man- 
agement measures in line with their own development and progress, and actively make clear regulations and plans from principles, methods, contents and practical means, which makes the internal control management measures of high-tech enterprises become an inevitable choice for the strict implementation of Chinese national laws and regulations. This is an important background for strengthening internal enterprise integration under legal conditions. In order to realize the internal control optimization of hightech enterprises, it is necessary to first regard budget management as an important management means for carrying out the corresponding work level improvement within the enterprise group. The first thing to do is to improve the budget management mechanism within the high-tech enterprises, so that all departments within the enterprise can guarantee their own economy and efficiency; secondly, it is necessary to establish a corresponding budget management department as the most basic and important decision-making body, and make a summary assessment of the budget management indicators and dynamic adjustments within the high-tech enterprises. ${ }^{[7]}$

\subsection{Improve the Cognitive Level of Managers}

As a senior manager of a high-tech enterprise, in order to effectively promote the improvement of the company's own economic benefits, it is necessary to first raise the level of awareness of managers' internal management information. Secondly, it is required to be able to formulate relevant policies and systems in the role of a corporate image leader and leader. However, in this process, we must always adhere to the application of the "people-oriented" concept; we must emphasize the equality of everyone before the system at an appropriate time, and effectively implement the economic policy. In addition, it is necessary to strengthen the level of relevant internal control managers, and require them to play a leading role in the actual work process, so as to implement the actual internal control work to specific places. The internal control management department of high-tech enterprises should regularly carry out the quality development activities of employees, and require them to have their own advantages and characteristics in the application of theoretical knowledge and practice level. Moreover, the cooperative participation of various activities also helps to improve the cohesiveness of the internal control management department, and the practitioners are freed from the boring work to relax.

\subsection{Standardize Internal Control Management Behaviors}

Since most of China's high-tech enterprises have many in- ternal management problems in terms of internal management, the overall situation shows a mixed state, moreover, most accounting and management work orders are unstable and irregular, and the corresponding financial revenues and expenditures occasionally run out of control, which has caused many problems such as accounting fraud and tax evasion in the process of improving the economic efficiency of high-tech enterprises. Through the research of relevant literature and the sum of a large number of practical cases, it can be clearly understood that the root cause is due to the lack of internal control of high-tech enterprises, which will not only give some opportunities for mentally unstable accounting crimes, but also bring greater harm and impact to the economic benefits of enterprises. Therefore, the realization of the control and optimization of the internal management of high-tech enterprises has become an objective requirement to effectively regulate the internal accounting behavior of enterprises. Moreover, for the development of the economic level of high-tech enterprises, the realization of corresponding internal control is, to a certain extent, an implementation of national policies, regulations and systems. Comprehensive monitoring and control helps to reduce the risks and harms faced by enterprises in the course of business, and ultimately provides real and reliable accounting information for the development of enterprises. The data transmitted by these kinds of information can actively act on the economic development of the entire high-tech enterprise. ${ }^{[8]}$

\section{Conclusion}

In summary, in terms of the long-standing old internal control system of enterprises, it is unable to meet the growing material needs at this stage. It is necessary to reform and innovate the financial management policies and related systems of high-tech enterprise units in the context of informationization, so that high-tech enterprise units can fully manage their operations in conjunction with the budget and promote the economic benefits of related enterprises. And as far as possible, all the internal control management work of the enterprise can be carried out in accordance with the principle of economical and economical, saving resources and strength.

\section{References}

[1] Minghua Shen. Research on Internal Control Management Problems and Countermeasures of Real Estate Development Enterprises[J]. Chinese \& Foreign Entrepreneurs, 2018(34):26-27. (in Chinese)

[2] Dapeng Tang, Yibo Wang. Problems and Countermeasures of Government Internal Control Man- 
agement Consulting $[\mathrm{J}]$. Finance \& Accounting, 2018(13):75-77. (in Chinese)

[3] Haili Liu. On the problems and countermeasures in the internal control management of high-tech enterprises[J]. Accounting Learning, 2017(15):244-245. (in Chinese)

[4] Yuting Wang. Analysis on the problems and countermeasures of internal control of growth-oriented high-tech enterprises_- Taking JL limited liability company as an example[A]. Singapore Management and Sports Science Institute, Singapore, Academic Conference Institute, USA. Proceedings of 2016 3rd International Conference on Management Innovation and Business Innovation (ICMIBI 2016 V58) [C]. Singapore Management and Sports Science Institute, Singapore, Academic Conference Institute, USA:
Intelligent Information Technology Application Association, 2016:7.

[5] Pengfei Ma. Analysis of the Influence of Internal Control on the Quality of Accounting Information[J]. Manager Journal, 2017(3):44. (in Chinese)

[6] Lin Ma. Analysis of the Impact of Internal Control on the Quality of Accounting Information in the New Period[J]. Money China (Academic Edition), 2017(1): 155-156. (in Chinese)

[7] Zhihua Gao. Analysis of Enterprise Internal Control Information Disclosure[J]. Guide to Business, 2015(8):155-156. (in Chinese)

[8] Juntao Guo. Discussion on Internal Control Management of Modern Enterprises[J]. Accounting Learning, 2016(2):117-118. (in Chinese) 